\title{
A DEFENSIVE FUNCTION FOR THE STABILIMENTA OF TWO ORB WEAVING SPIDERS (ARANEAE, ARANEIDAE)*
}

\author{
By Charles C. Horton \\ Department of Biological Sciences \\ University of Maryland Baltimore County (UMBC) \\ 5401 Wilkens Avenue \\ Catonsville, Maryland 21228
}

Stabilimenta consist of straight or zigzag bands of ribbon silk which are arranged in species and age-specific patterns within the free zone and sometimes the hub of the webs of many diurnally active orbweaving spiders, including members of both major families of orbweavers (Araneidae, Uloboridae). The relatively common occurrence of stabilimenta among the orb-weaving guild suggests that they have one or more important functions. Although a number of functions have been suggested (see Robinson and Robinson, 1970, 1973), the actual significance of any of these proposed functions has not yet been demonstrated (Levi, 1978). I present here experimental evidence which suggests that the stabilimenta of Argiope aurantia Lucas and $A$. trifasciata (Forskal) aid in defense against avian predators.

The stabilimenta of all but the early instars of $A$. aurantia and $A$. trifasciata are vertical zigzags of silk located above and/or below the hub, where the spider rests. Early instars of A. aurantia, as well as the early intars of several other Argiope spp. produce a disc stabilimentum. The vertical stabilimentum is also constructed by other Argiope sp. (e.g. A. bruennichi, A. lobata). Some Argiope spp. produce a cross stabilimentum composed of zigzags of ribbon silk arranged in the pattern of an "X" around the hub (e.g. A argentata, A. florida, A. pulchella, A. savignyi). All Argiope spp. produce some form of stabilimentum (Levi, 1968).

Argiope spp. reside during daylight hours at the hub of the web, a position which exposes them to potential predators. This exposure to potential predators suggests a defensive function for stabilimenta. Defensive functions for the stabilimenta of Argiope spp. have been suggested by various authors (Hingston, 1927; Marson, 1947; Lubin,

*Manuscript received by the editor August 23, 1980. 
1975; Tolbert, 1975) based on observations on natural populations. However, Robinson and Robinson (1970) performed experiments using model stabilimenta which indicated that birds could use stabilimenta as an aid to prey location. Thus, the defensive role of stabilimenta is not clear.

I performed experiments in aviaries which consisted of exposing blue jays to a simultaneous choice among $A$. aurantia or $A$. trifasciata which exhibited different degrees of web completion, in order to assess the effect of the stabilimentum on avian predation.

\section{Materials And Methods}

The experiments were performed in aviaries which consisted of $1.6 \times 6.2 \times 2.3 \mathrm{~m}$ wire mesh enclosures located on the roof of Morrill Science Center, University of Massachusetts, Amherst. The basic experimental design was to offer blue jays (Cyanocilla cristata) a choice among three spiders, each in a web at a different stage of completion; (1) suspended in the characteristic resting position, but entirely out of a web; (2) in a web without a stabilimentum; and (3) in a web with a stabilimentum.

The blue jays used in the experiments had been taken as nestlings from their nests in the Amherst area and reared by hand. Thus they were naive with respect to spiders and their webs prior to experimentation. The blue jays were kept individually in the aviaries for several days prior to experimentation. Each bird was trained to recognize spiders as food by placing living spiders in its food tray (i.e., spiders free of webs). A given bird was used in the experiments when it took spiders readily (three within five minutes) without having previously been deprived of food. Prior to experimentation the birds were deprived of food overnight. Nine birds wre used, each bird being used one to four times. An attempt was also made to use starlings (Sturnus vulgaris) and robins (Turdus migratorius) in the experiments; they were found to be unsuitable.

Penultimate and adult female $A$. aurantia and $A$. trifasciata were collected from field areas in and near Amherst, Massachusetts. The size and species of the spiders were the same within each choice set. In some cases, 6-12 spiders were released into the aviary during the evening prior to experimentation, while the bird was isolated in a small cement-block enclosure $(1.5 \times 2.1 \times 1.4 \mathrm{~m})$ at the rear of the aviary. Most of the spiders selected suitable web sites and built their 
webs within the aviary during the night and early morning. Three spiders were then selected-one having no web, one having a web without a stabilimentum and one having a complete web. The remaining spiders and their webs were removed. If none of the spiders had produced a web without a stabilimentum one web was randomly selected and its stabilimentum removed with a hot needle. The "nonweb" spider was a spider which had suspended itself on a few strands in the normal resting position.

In other cases the spiders used in the experiments had built their webs within aluminum frames $(50 \times 50 \times 5 \mathrm{~cm})$ with glass panels in the front and back which were removed prior to placing the frames in the aviaries. During an experiment, two of the frames contained spiders in webs, one with, and one without a stabilimentum. The third frame contained a spider which had been killed by freezing and was suspended by thread in the characteristic resting position in the center of the frame. The frames were placed in random order side-by-side on a table within the aviary. The data obtained from the experiments using spiders in frames were combined with data from spiders which had constructed their webs within the aviary.

The second set of experiments was performed using pen and ink drawings of orb webs. These drawings were executed in white ink on a brown background, and were approximately the size of a normal, adult Argiope web. The drawings were suspended within the aluminum spider frames, using the same three web conditions used in the previous experiment. Crickets were suspended by thread in the position that would normally be occupied by the spider. The blue jays used were trained to recognize crickets as food, and were naive with respect to spiders and spider webs.

Once the three webs or web drawings were in place, a blue jay was released into the aviary. Capture sequence, capture time, and the behaviors exhibited by the blue jays and the spiders were recorded. An attempt to capture a spider which resulted in only a portion being taken was scored as a capture.

The null hypothesis in the experiment outlined above was that the web and stabilimentum would have no effect on predation. The alternative hypothesis was that these structures would inhibit predation. If the null hypothesis were valid, the capture sequence (i.e., which spider/cricket was taken first, second, third) would have been random. A nonrandom sequence, in which the non-web spider tended to be taken first, the partial web spider second, and the full web spider last, would support the alternate hypothesis. 


\section{Results AND Discussion}

The results are divided into two groups. The first grouping is the response of inexperienced birds upon their first exposure to the choice between a non-web spider, a spider in a partial web, and a spider in a full web. The second group consists of all the succeeding response sequences of the birds which were used more than once.

Table 1 shows the first capture exhibited by 11 birds on their first exposure to the experimental situation. These birds had had no previous experience with spiders in webs, but had had experience with spiders out of webs (in feeding trays). Although the data are too few to detect minor preferences, the first choice of the birds appears to have been random, suggesting that the birds had no innate aversion to spider webs and/or stabilimenta.

Table 1. First Choice Among Three Web Conditions Exhibited by 11 Inexperienced Blue Jays. "N" Stands for the Non-web Spider, "P" the Partial-web Spider, and "F" the Full-web Spider.

\begin{tabular}{cc}
\hline Possible & Number of \\
Choices & Times Observed \\
N & 5 \\
$\mathrm{P}$ & 3 \\
$\mathrm{~F}$ & 3 \\
\hline
\end{tabular}

Although the first choice appears random, some degree of innate preference among the three choices cannot be ruled out on the basis of these data. It has been shown that slight differences in the stimulus pattern presented by Lepidoptera prey can alter or prevent the initial attack response of blue jays (Coppinger, 1968), and during my experiments the blue jays were confronted with a choice among three stimulus patterns which differed with respect to visual complexity. Thus, the discrimination shown by the blue jays in response to the spiders in their webs could have been affected by the differences in visual stimulus patterns among the choices. Accordingly, eight birds were given similar choices, using, however, web drawings and crickets as prey. In these experiments the visual stimulus pattern was essentially the same as in the experiment outlined above, but the tactile element of the web was missing.

The results of the experiment with web drawings and crickets are summarized in Table 2. A Chi-square analysis indicates that the 
Table 2. Capture Sequences Exhibited by 8 Blue Jays Given a Choice Among 3 Crickets and Web Drawings

\begin{tabular}{cc}
\hline $\begin{array}{c}\text { Possible } \\
\text { Capture } \\
\text { Sequences }\end{array}$ & $\begin{array}{c}\text { Times } \\
\text { Observed }\end{array}$ \\
\hline N-P-F & 6 \\
N-F-P & 3 \\
P-N-F & 2 \\
P-F-N & 7 \\
F-N-P & 7 \\
F-P-N & 5 \\
\hline
\end{tabular}

distribution of capture sequences did not differ from random $(\mathrm{P}>0.50)$, indicating that the blue jays did not discriminate among the three web drawings. The web drawings were of course not identical to the spider webs. However, the results suggest that the birds had no innate preferences among the three web conditions.

Table 3 shows the observed capture sequences exhibited by six experienced birds (i.e., excluding the initial sequence of each bird). Of the six birds, four were used twice and two were used three times. The results clearly favor rejection of the null hypothesis since the probability of this or a more extreme distribution is $<0.001$ (binomial expansion) (Steel and Torrie, 1976).

The non-web spider was taken first in 13/14 of the cases, demonstrating that non-web spiders were preferred over spiders within webs. In these cases the birds were left with a choice between a complete web and a partial web (one which lacked a stabilimentum).

Table 3. Capture Sequence Exhibited by Six Experienced Blue Jays Given a Choice Among Three Spiders (Abbreviations as in Table 1)

\begin{tabular}{cc}
\hline $\begin{array}{c}\text { Possible } \\
\text { Capture } \\
\text { Sequences }\end{array}$ & $\begin{array}{c}\text { Times } \\
\text { Observed }\end{array}$ \\
\hline N-P-F & 12 \\
N-F-P & 1 \\
P-N-F & 1 \\
P-F-N & 0 \\
F-N-P & 0 \\
F-P-N & 0
\end{tabular}


These birds selected the spider on the incomplete web 12/13 times. The results of the second choice are also clearly non-random and demonstrate that the stabilimentum had a negative influence. The results show that both the web and the stabilimentum inhibited predation by the blue jays.

Comparison of the results obtained during the initial exposure of each bird with the results from subsequent trials indicates that this avoidance of webs and stabilimenta is a learned response. Initially the birds did not discriminate between the three choices, but they did so after experiencing web contact.

After having contacted the webs the blue jays exhibited behaviors such as head shaking, wiping the beak, and preening. The birds displayed these cleaning behaviors for periods ranging from 30 seconds up to an hour after web contact. The web adhered to the feathers and caused some clumping, mainly of the head and breast areas. Cleaning activities were apparently directed at removal of the portions of the web which had adhered to the birds.

It is possible that the web contains a substance which is noxious or toxic to birds when ingested. However, during the experiments, I observed some of the birds eating the webs after coming in contact with them. The fact that the birds ate the portion of the webs which adhered to their feathers suggests that the web did not contain noxious or toxic substances.

Based on the behaviors exhibited by the blue jays, I suggest that the noxious quality of the web is due to the physical adherence of the web to the bird's feathers, and the resulting clumping of the feathers.

Apparently stabilimenta are constructed only by diurnally active orb-weavers. A second generalization is that many of the diurnal orbweavers are conspicuously colored (Levi, 1968). Since it appears that the web is a noxious stimulus to birds, then it is reasonable to suggest that both the conspicuous coloration of the spider and the presence of stabilimenta make the web more obvious, thus facilitating avoidance by predators. The stabilimentum would then be analogous to aposematic (warning) coloration in insects. The stabilimentum and bright coloration would have an effect on visually orienting predators, such as birds, and would be effective during daylight hours when such predators are active. This hypothesis of advertisement was originally discussed by Robinson and Robinson (1970), though they had no evidence of a noxious element. 
The observations of Robinson and Robinson (1970) which demonstrated that the cross stabilimentum could be used by birds as an aid in prey location also indirectly supports my hypothesis. Their experiments demonstrated that birds could key in on the stabilimentum. However, in their study the model stabilimenta were paired only with a positive reinforcement (prey), resulting in attraction of the birds. In the natural situation, the stabilimentum probably facilitates avoidance, rather than attraction of predators, since it is paired with a negative stimulus, the webs.

\section{ConClusions}

Experiments performed with blue jays in aviaries showed that the birds preferred spiders which were not in their webs. A comparison of the behavior of inexperienced birds with that of the same birds after contacting the webs suggests that web avoidance is a learned response. This avoidance of contact with the web indicates that the orb-web constitutes a noxious stimulus to blue jays, and presumably to other avian predators. The noxious element appears to be the adherence of the web to the bird's feathers, as indicated by extended bouts of cleaning behavior exhibited by the blue jays following web contact.

The experiments also show that the stabilimenta of $A$. aurantia and $A$. trifasciata enhance the web avoidance response exhibited by blue jays. I propose that the stabilimenta of these species "advertise" the presence of the web, a noxious stimulus, in a manner analagous to aposematic coloration of some insects. The advertisement hypothesis of stabilimentum function does not exclude the possibility of other functions for this structure.

The hypothesis that the web and stabilimenta inhibit avian predation is compatible with previous observations concerning the occurrence of stabilimenta in other araneids, suggesting the general applicability of the hypothesis. For example, as previously noted, stabilimenta are only constructed by diurnal orb-weaving spiders. Since nocturnal orb-weavers as a rule rest in a retreat near the periphery of the web during the day, residing in the hub only at night, they would be less exposed to visually orienting predators. Thus, according to this hypothesis, it would be predicted that the diurnally active araneids would be more likely to construct stabilimenta. A second observation concerning diurnal orb-weavers is that, in 
general, they are conspicuously colored (Levi, 1968). This bright coloration could serve as additional advertisement of the web as a noxious stimulus.

\section{ACKNOWLEDGEMENTS}

Many persons have given me advice during this study; in particular I acknowledge the ideas and suggestions of Theodore D. Sargent, William B. Nutting, and Carolyn Cearley. I would like to thank Alan C. Kamil for providing the blue jays used in the study. This work represents a portion of a thesis submitted in partial fulfillment of the requirements for the Ph.D degree at the University of Massachusetts. A portion of the support for this study came from a Sigma Xi grant in the aid of research.

\section{REFERENCES}

Coppinger, R.P. 1968. The effect of experience and novelty on avian feeding behavior with reference to the evolution of warning coloration in butterflies. Ph.D. thesis (unpublished), Amherst College, Amherst, MA 01002.

Hingston, R.W.G. 1927. Protective devices in spiders' snares. Proc. Zool. Soc. Lond. 18: 259-293.

Levi, H.W. 1968. The spider genera Gea and Argiope in America (Araneae: Araneidae). Bull. Mus. Comp. Zool. Harvard 136: 319-352.

1978. Orb-weaving spiders and their webs. Sci. Amer. 66: 734-742.

Lubin, Y.D. 1975. Stabilimenta and barrier webs in the orb webs of Argiope argentata (Aranea, Araneidae) on Daphne and Santa Cruz Islands, Galapagos. J. Arach. 2: 119-126.

Marson, J.H. 1947. Some observations on the ecological variations and development of the cruciate zigzag camouflage device of Argiope pulchella (Thor.) Proc. Zool. Soc. Lond. 117: 219-227.

Robinson, M.H. AND B. Robinson. 1970. The stabilimentum of the orb web spider, Argiope argentata: an improbable defence against predators. Canad. Entomol. 102: 641-655.

1973. The stabilimenta of Nephila clavipes and the origins of stabilimentum-building in araneids. Psyche 80: 277-288.

SteEl, R.G.D. AND J.H. Torrie, 1976. Introduction to Statistics. McGraw-Hill Book Company.

TOLBert, W.W. 1975. Predator avoidance behavior and web defensive structures in the orb weavers Argiope aurantia and Argiope trifasciata (Araneae, Araneidae). Psyche 82: 29-52. 



Submit your manuscripts at

http://www.hindawi.com
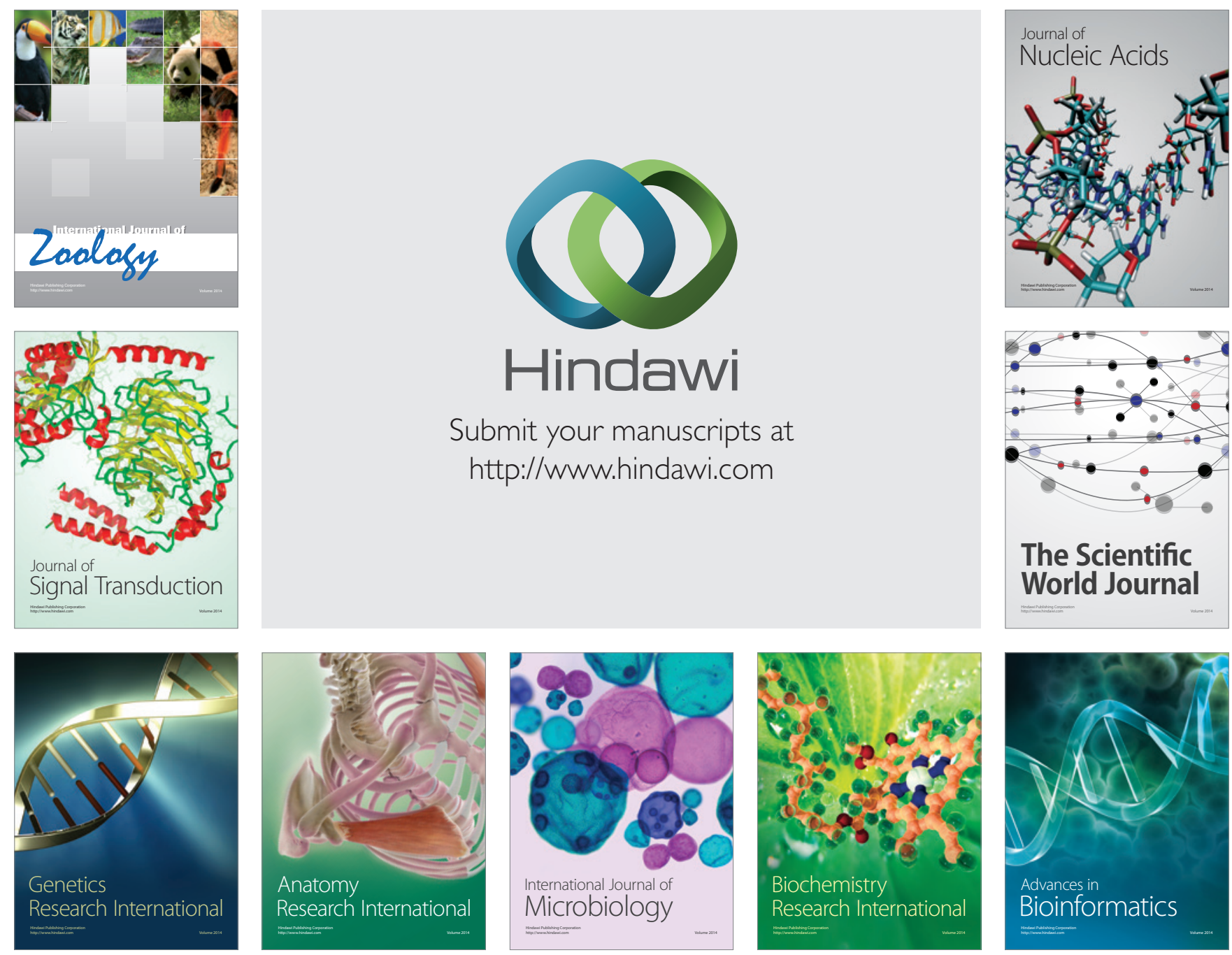

The Scientific World Journal
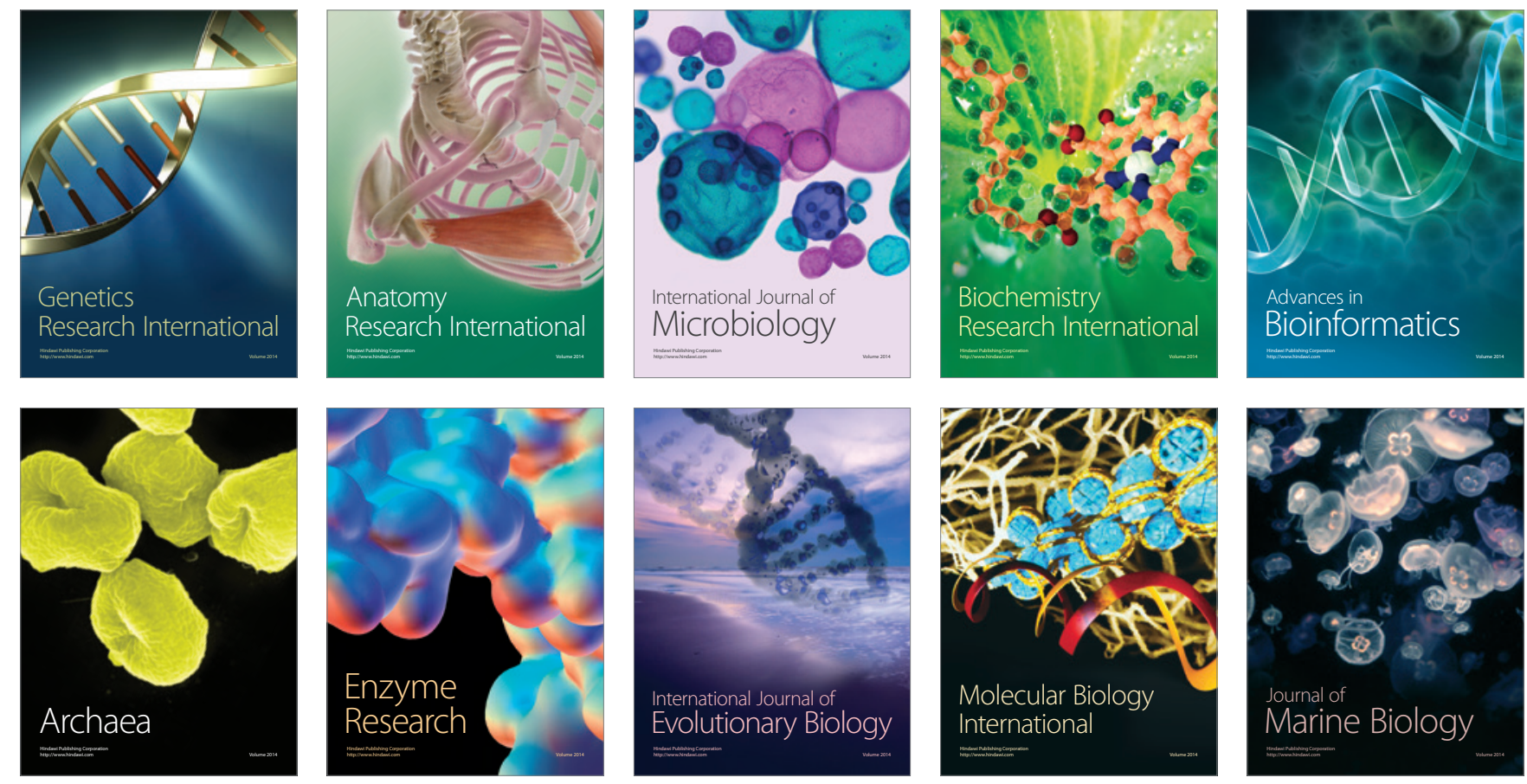